\title{
ROMENCEDE BULUNAN TÜRKÇE SÖZCÜKLERDEKİ ANLAM KAYMALARI
}

\author{
Hatice KUTLAR*
}

\begin{abstract}
ÖZET
Osmanlı İmparatorluğu öncesinde de Balkan yarımadasında var oldukları bilinen Türkler, Balkan halklarının siyasi, ekonomik, sosyal hayatlarında ve dillerinde derin izler bırakmışlardır. Balkan dillerindeki Türkçenin izleri üzerine 19. yüzyıldan günümüze özellikle oryantalizm Türkizm veya Balkanizm başlıkları içine dâhil edilen pek çok araştırma yapılmıştır ve bu araştırmalar günümüzde de devam etmektedir. Romence üzerine yapılan çalışmalar da bu konu içinde değerlendirilmektedir. İlk oryantalistlerin başlattığ 1 bu çalışmalarda Türkçenin Romence üzerindeki etkisi araştırılıp ödünçlemeler adı verilen söz varlığı grubu incelenmiştir. Bugünkü çalı̧̧malar ise daha çok Romencedeki bu verintilerin günümüzdeki durumuyla ilgilidir.
\end{abstract}

Alıntı sözcükler yöneten-yönetilen ilişkisi, komşuluk, prestij ve saygınlık kazanma gibi çeşitli sebeplerle başka bir dilden alınan, başlangıçta alıcı dilin söz varlığının bir parçası olmayan, ancak zamanla o dilin söz varlığına dâhil olmuş sözcüklerdir.

Bir dilin söz varlığında bulunan bir sözlük biriminin tarihsel süreç içinde kazandığı yeni anlamlar, kaybettiği anlamlar, sonraki dönemde taşıdığı olumlu veya olumsuz anlamlar, anlam bilimi içinde çalışılan ve anlam değişmelerini ilgilendiren konular olmuştur. Bu konulardan biri de anlam kaymasıdır. Anlam kayması, anlam değişmelerinin inceleme konuları arasındadır ve anlam bilimi çalışmalarında en çok çalışılan konulardan biridir.

Bu çalışmanın konusunu Türkçeden Romenceye geçen Türkçe kökenli sözcüklerin Romencedeki kazandıkları yeni anlamlar, mecazlaşmış deyimler, yani anlam kayması olayları oluşturur. Romencede bulunan Türkçe alıntı sözcükler üzerine yapılmış olan çeşitli çalışmalardan hareketle, bu kaynaklardaki sözcükler taranarak ve Türkçe Sözlük'teki anlamlarıyla karş̧laştırılarak, anlam kayması olarak değerlendirilen 197'si isim, 11'i fiil, toplamda 208 sözcük tespit edilmiştir. Bu sözcüklerin anlam yapısı bir yandan kısmen korunurken, öte yandan ödünçlemenin anlamından bağımsız, farklı ve yeni anlamlar da ortaya çıkmıştır. İncelediğimiz sözcüklerin de içinde yer aldı̆̆ı Romence deyimlerin sayısı ise 59 olarak tespit edilmiştir.

Anahtar Sözcükler: Dil ilişkileri, Balkanizm, oryantalizm, Romence, alıntılar, ödünçlemeler, anlam kaymasi.

\section{THE MEANING CHANGES IN THE TURKISH WORDS IN ROMANIAN LANGUAGE}

\section{ABSTRACT}

The Turks, known to have existed in the Balkan peninsula before Ottoman Empire, left deep traces in the political, economic, social lives and languages of the Balkan peoples. Many studies have been carried out on the traces of Turkish in the Balkan languages from the 19th century to the present under the titles Orientalism, Turkism or Balkanism. Studies on Romanian are also considered within this subject. In these studies initiated by the first Orientalists, the effect on

\footnotetext{
* Dr. Öğr. Üyesi, Sivas Cumhuriyet Üniversitesi, Edebiyat Fakültesi, Çağdaş Türk Lehçeleri Bölümü e posta:Tice.Kutlar@gmail.com
} 
Turkish on Romanian was investigated and the vocabulary group called borrowings was examined. Today's studies are mostly related to the current situation of these data in Romanian.

Borrowings are words that are taken from another language for various reasons such as the relationship between the ruler and the ruled, neighborhood, prestige and gaining prestige, initially not a part of the vocabulary of the recipient language, but gradually incorporated into the vocabulary of that language.

The new meanigs that a lexical unit in the vocabulary of a language gained in the historical process, the meanings it lost, the positive or negative meanings it carried in the next period have been the subjects studied in semantics and related to the meaning changes. One of these issues is the shift in meaning. Semantic shift is among the topics of study of meaning changes and it is one of the most studied topics in semantics studies.

The subject of this study is the new meanings, metaphorized idioms, that is, the events of meaning shipt, gained by the words of Turkish origin passing from Turkish to Romanian in Romanian. Based on various studies on Turkish quoted words in Romanian, the words in these sources were scanned and compared with their meanings in the Turkish Dictionary, 197 nouns, 11 verbs, and 208 words in total were identified. While the semantic structure of these words is partially preserved, different and new meanings have emerged, independent of the meaning of the meaning of borrowing, on the other hand. The number of idioms created by these lending words lexicographic units gaining new metaphor meanings is 59.

Keywords: Language relations, Balkanism, Orientalizm, Rumanian, loanwords, borrowing, semantic drift.

\section{Giriş}

Türkçe, tarih boyunca Balkanlar'daki mevcut bütün halkların dillerini etkilediği gibi Romenceyi de etkilemiştir. Yaklaşık 500 yıl süren Türkler ve Romenler arasındaki tarihî ve siyasi ilişkiler, kültürel bir etkileşime sebebiyet vermiş, bu durum dil boyutuna da yansımıştır.

Balkanlar'da Osmanlı öncesinde de Türk topluluklarının etkisi tespit edilmiş olmakla birlikte, Osmanlı döneminde fethedilen toprakların imarı, kurulan şehirler ve bu şehirler etrafında oluşan Türk-İslam kültür havzası Balkan topraklarında kalıcı, derin ve sonuçları günümüze kadar gelen büyük bir etkinin ortaya çıkmasına vesile olmuştur (İyiyol 2011: 623).

Osmanlı İmparatorluğu'nun Balkanlar üzerindeki askerî, siyasi, sosyoekonomik etkileri 16. yüzyıldan sonra giderek artmıştır. İslamiyet'i kabul etmeyen ve reaya konumunda bulunan Romenler, "İslamlaşan topluluklar kadar olmasa da Osmanl1Türk kültürünün derin tesirini yaşamışlardır" (İyiyol 2004: 623). Osmanlı'nın Balkanlar'daki varlığı 19. yüzyılın sonlarında Rusların Balkanlar'a girişi ve bunu takip eden 93 Harbi yenilgisiyle son bulur. Türkçe bu zaman dilimi içinde bütün Balkan dilleri için bir Lingua Franca, yani Prestij Dil konumunda olmuştur.

En temel ve kaçınılmaz bir dil bilimi olayı olan ödünçlemeler, dilin canlı ve sürekli oluşu sebebiyle toplumların ilk karşılaştıkları zamanlardan itibaren ortaya çıkarlar. Ödünçleme (İng. borrowing), dil bilimsel bir unsurun bir dilden başka bir dile aktarılmasıdır. Bu yazıda kullanmayı tercih ettiğimiz ödünçleme ve alıntı terimlerinin dişında kabul gören terimlerden birisi de kopyalama terimidir. "Johanson diğer terimlerle ilgili çekincelerini temellendirmiş, diğer terimler 
yerine dil gerçeğini daha iyi yansıtan kopyalama terimini önermiştir" (Demir 2003:3). Ödünçleme sürecinin sonucu olarak alıntı /verinti (İng. quoted) kavramları ortaya çıkar. "Bir dilin tarihine 1şık tutan ve dilde meydana gelen değişmeleri izleme imkânı sağlayan bu veriler; tarih, sosyoloji gibi birçok disiplin için ayrıca önemlidir" (Uysal 2020: 13).

Alıntı sözcükler, bir dilden başka bir dile geçerken zaman içinde geçtiği dilin söz varlığına da etki ederler. Yöneten-yönetilen ilişkisi ile başlayan dil ilişkileri zamanla karşılıklı bir öğretme-öğrenme ilişkisine dönüşerek, her iki dilde bilgi temelli alıntıları ortaya çıkarır. "Türkçe ile Türkçeye komşu olarak yaşamış ve yaşamakta olan diller arası ilişkilerin tespiti demek, bir ölçüde, Türklerle komşuları arasındaki ilişkilerin tespiti, Türklerin komşularına öğrettikleri ile komşularının Türklere öğrettiklerinin belirlenmesi demektir" (Karaağaç 1998: $363)$.

Türkçenin Romence üzerindeki etkisi 19. yüzyıla kadar devam etmiştir. Dil ilişkisinin kısmen sona ermesi, yöneten- yönetilen ilişkisinin yani siyasi ilişkilerin sona ermesiyle ilişkilidir; yöneten-yönetilen ilişkisi kaynaklı alıntılar ve idari terimler Romenceden çekildikden sonra, geriye uzun yüzylllar boyunca kültür alışverişi içindeki halkların ve onların dillerinin birbirlerine bir şeyler öğretmesiyle ilgili olan ödünçlemeler kalır; bunların kalıcığı neticesinde de verintiler adını alan sözcük grupları oluşur. Her dil için verintiler, o dilin söz varlığına dâhil edilen ve o dilin söz varlığını zenginleştiren unsurlardır (Karaağaç, 2008).

"Dil etkileşimleri, temas hâlindeki dilleri ses bilgisinden söz dizimine kadar pek çok boyutta etkiler" (Özkan 2004: 294). Sadece söz varlığı üzerindeki etkisi de dar bir etki olmakla birlikte önemli bir etkidir. Ancak bu etkinin daha ileri bir boyutu, verici dilin ekleri ve cümle yapılarındaki kopyalamalar, yani gramerlik alıntılardır. İlişkilerin yoğun yaşandığı dönemde binlerce Türkçe sözcük Romenceye girerek bir dil zenginliği oluşturmuştur. Romencenin Türkçeden yapmış olduğu alıntılar (dolayısıyla Türkçenin Romenceye verintileri) sadece sözcük alıntısı düzeyinde kalmayarak Romencenin dil bilgisi ve deyim boyutuna da sıçramıştır.

Balkanlar'da Türk ve Osmanlı kültürünün etkileri üzerine yapılan çalışmalar genellikle Türkizm, oryantalizm ve Balkanizm gibi başlıklar altında değerlendirilmektedir ${ }^{1}$. Balkan dillerindeki Türkçe sözcükler de 19. yüzyıldan itibaren pek çok dil bilimci için bir çalışma konusu olmuştur.

Otto Blau, Osmanlı Türkçesinin Balkan dillerine etkisini ilk araştıranlardan biridir. O. Blau'dan sonra bu konudaki çalışmalar da hız kazanmıştır. Günümüzde bu konuyla ilgili geniş bir literatür bulunmaktadır.

Kendisi de bir Romen olan L. Šaineanu, yaptığı kapsamlı çalışmasında Romencede bulunan 3900 Türkçe unsuru tespit etmiştir. Bu konuda yapılan son çalışmalardan birini hazırlamış olan $\mathrm{M}$. Nurlu ise, günümüzde yaşamaya devam

\footnotetext{
${ }^{1}$ Türkizm ve oryantalizm terimleri etrafindaki tartışmalar için bk. İyiyol 2011: 621-632.
} 
eden sözcüklerin sayısını 1200 olarak verir. Konuyla ilgili hazırlanan çalışmalarda ve kaynaklarda farklı sayılar olmakla birlikte, Türkçe Verintiler Sözlüğ̈̈'nde kaydedilen Romence sözcüklerin sayısı yaklaşık 3000 civarındadır. Ciorănescu tarafindan hazırlanan Romen Dili Etimolojik Sözlügü̈nde ise Türkçe kökenli olarak tanımlanan sözcükler 2000 civarındadır.

Romencede bulunan binlerce Türkçe sözcügün büyük bir kısmı bugün eskimiş, kullanılmayan bir söz hazinesi durumundadır; öte yandan 350-400 civarındaki sözcük, günlük hayatta kullanılmaya devam eden, yaşayan sözcüklerdir. "geam, cazan, iaurt, telemea, pilaf, caimac, sarma, ghiol, chior ve bunlar gibi başka kelimeler günlük yaşamda çok sık kullanılmalarının yanı sıra, Romencede bu Türkçe kelimelerin yerini tutacak başka eş anlamlı karşılıkları" yoktur. (Baubec 2016: 21)

Bu çalışmada, Romencede bulunan ve Türkçeden ödünçlenen sözcüklerin sadece Türkçe kökenli olanları değerlendirilerek, Romenceye girdikleri dönemden itibaren günümüze kadar bu sözcüklerde meydana gelen ve anlam biliminin inceleme konuları arasında yer alan anlam değişmeleri ve bu değişmelerden biri olan anlam kaymaları üzerinde durulacaktır.

\section{Anlam Değişmeleri ve Anlam Değişmelerinin Sebepleri}

Soyut bir olgu olması, çoğu zaman belirsiz olması ve değişkenlik göstermesi sebebiyle anlam sözcüğünün tanımının yapılması güç olmuştur. Bu sebeple de bir anlam bilimi terimi olarak anlam sözcüğünün pek çok tanımı bulunmaktadır. Anlam sözcüğünün tek bir tanımının yapılamaması ve yapılan tanımların da tartışılır olması, o sözcüğün yeni bir bilim dalını ilgilendiren bir terim olması yanında, dil bilimsel ve felsefi bir terim/kavram olması sebebiyledir. Türkçe Sözlük (2011)'te bir dil bilimi terimi olarak anlam sözcüğü şöyle tanımlanmıştır: "Bir kelimeden, bir sözden, bir davranış veya olgudan anlaşılan şey, bunların hatırlattığı düşünce veya nesne, mana, meal, fehva, deme, mazmun, medlul, valör."

Anlam değişmeleri ise, bir sözcüğün daha önceki anlamına göre farklı etkenlerle ve zamanla anlamında değişiklikler olması olayıdır.

Anlam bilimi, gösterge biliminden sonra dil biliminin alt dallarından biri olarak 19. yüzyılda doğan yeni bir bilim dalıdır. Kaynaklarda farklı şekillerde tanımlanan anlam biliminin konusunu "kelime nedir, kelimenin anlamları nelerdir, fonksiyonları nelerdir, bir kelimenin biçimi ve anlamı arasındaki bağıntılar nelerdir, kelimeler arası ilişkiler nelerdir, kelimeler görevlerini nasıl yaparlar?" gibi soruların cevapları oluşturur (Atmaca 2011:485).

Anlam değişmeleri konusu ise, anlam biliminin çalışma alanı içinde yer alır. Anlam değişmeleri, anlam biliminin önemli inceleme konularından biridir ve üzerinde en fazla durulan konudur. Türkiye'de de özellikle 1990'lı y1llardan sonra bu konuda önemli çalışmalar yapılmıştır.

Her dilde, o dilin gelişimi boyunca, genellikle de uzun bir zaman içinde sözcüklerde anlam değişiklikleri olur. Dilin doğal işleyişi içinde bu konuda yine 
toplumsal bir kabul ve uzlaşı olması da söz konusudur. Bir dilde bulunan alıntı sözcüklerde de zaman içinde böyle bir değişikliğin olması doğaldır. "Alıcı dil kendi algısına, ihtiyaçlarına ve düşünce sistemine göre aldığ sözcüğe anlam/anlamlar yükler. Zaman içinde fonetik ve morfolojik dönüşüm ve üstlendiği özgün anlamlarla alıntılanan sözcük, artık yeni dilinin öz malzemesi hâline gelir" (Bayraktar 2015: 2).

Anlam bilimi çalışmalarını başlatan Batılı anlam bilimciler, anlam değişmeleri üzerine yaptıkları çalışmalarında değişik sınıflandırmalar ve değerlendirmeler yapmışlardır. $\mathrm{Bu}$ sebeple anlam değişmeleriyle ilgili yapılmış olan siniflandırmalar, kullanılan terimler veya kategorilerin incelenmesi bakımından farklılık göstermektedir. Anlam değişmeleri, bu konuda farklı değerlendirmeler olsa da genellikle 5 başlık altında incelenmektedir ${ }^{2}$ :

I) Anlam kayması (İng. semantic drift), göstergenin eski kavramlarının dışında farklı kavramlar edinmesidir.

II) Anlam daralması (İng. semantic restriction), göstergenin eski kavramlarından birinin kullanılmaz oluşu ve sözcüğün belirli ve sınırlı bir bağlamda kullanılmasıdır.

III) Anlam genişlemesi (İng. semantic extention), anlam daralmasının tersine göstergenin önceki/mevcut anlamını kaybetmeden yeni kavramlar kazanmasidır.

IV) Anlam iyileşmesi (İng. amelioration), göstergenin eski olumsuz anlamından daha olumlu bir anlam taşımasıdır.

V) Anlam kötüleşmesi (İng. pejoration), göstergenin eski olumlu anlamından daha olumsuz bir anlam taşımasıdır (Özkan 2019: 36-44).

Anlam bilimi incelemelerinde genellikle art zamanlı inceleme yöntemi kullanılır.

Alıntı sözcüklerdeki "bazı anlam değişmelerinin tam olarak neden kaynaklandığı, sürecin hangi yönde ve ne tür etkilerle şekillendiği kesin bir şekilde ortaya konulamasa da" (Koca 2021:7), bazı anlam değişmelerinin (İng. semantic change) sebepleri arasında içsel, yani dil bilimsel sebepler olabileceği düşünülmektedir. "Anlam değişmesinin dil bilimsel olmayan sebepleri arasında o dili konuşanların yaşamış olduğu tarihî, kültürel, toplumsal ve psikolojik değişikliklerin yanı sıra toplumsal ihtiyaçlardaki farklılık da birinci derecede etkilidir. Bilimsel, kurumsal veya töresel değişmeler de bu doğrultuda anlam değişmesine sebep olabilir" (Şahru 2019:141).

Fransız dil bilimci A. Meillet, anlam kaymalarının belli başlı sebepleri olarak dilsel, tarihsel ve sosyal sebepleri gösterir. Ancak bu sebeplere etki eden farklı etmenler de bulunmaktadır: bir ihtiyacın oluşması, toplumsal ve kültürel gelişim, psikolojik ve duygusal durumlar, dilsel bozulmalar, mecazi değişimler, yaratıcılık gibi. Romencenin kendi iç dinamiklerinden doğan dil bilimsel sebeplerinin

\footnotetext{
${ }^{2}$ Aksan (2009: 88-94), anlam değişmelerini 6 başlık altında inceler: 1) Başka anlama geçiş, 2) anlam daralması, 3) anlam genişlemesi, 4) genelleşme, 5) anlam iyileşmesi, 6) anlam kötüleşmesi.
} 
dışında bağlamla ilgili olan anlam, kolektif ve bilinçsiz bir şekilde toplumsal bağlamla ilgili değerlendirmede temel anlamın yerini alabilir.

Nihayet, alıntı sözcükler de "zamanın ruhuna, dönemin kültürel beğenisine ve dillerin iç düzenine ve de toplumlar arası etkileşime bağlı olarak ya kısmi ya da tamamen değişime" uğrayabilir (Karaağaç 1997: 100).

\subsection{Anlam Kayması}

Anlam kayması, anlam değişmelerinin asıl konusunu oluşturur. Genellikle anlam kayması olarak adlandırılan anlam değişmeleri için de anlam biliminde değişik terimler kullanılmıştır ${ }^{3}$.

Anlam kaymasında gösterge, ilk anlamıyla ilişkili olmayan farklı bir anlamı yansitır. Anlam kaymasında "gösterge yani varlığa verilen ad değil, isimlendirilen şey yani gösterilen değişikliğe uğrar" (Şahru 2019: 144).

Anlam kayması olayları kendi içinde sınıflandırıldığında, üç grupta incelenebilir (Selçuk 2010:5):

a) Birinci dereceden anlam kaymalarında bir kelime eski anlamını bırakarak, yepyeni ve farklı bir anlamı karşılar duruma gelir.

b) Birden fazla anlamlı sözcüklerde, anlamlardan en az biri eski anlamını korumakla birlikte, sözcüğün diğer bir ya da birden fazla anlamları öncekine göre başka, yepyeni bir kavramı karşılayabilirler.

c) Bazı sözcüklerde iki veya ikiden fazla anlam değişmesi özelliği ortaya çıkabilir. Bu değişimlerin sebebi zaman olabileceği gibi, tarihî ve siyasi sebeplerle aynı anda böyle bir değişim ortaya çıkabilir.

Aşağıda incelenen Romencenin Türkçe ödünçlemelerinde bu üç durumu da görmek mümkündür.

\section{Yöntem}

Bu çalışmada Romencenin söz varlığına etki eden, yeni bir dil bilimsel birim halini alan ve bir sözlük alıntısı olarak kabul edilen Türkçe kökenli ödünçlemelerin Romencenin sözlüksel-anlamsal gelişmesi içindeki durumu ve Romencenin sözlüksel yapısının zenginleşmesindeki rolü tespit edilmeye çalışılmıştır.

Çalışmamızda Türkçeden Romenceye geçen ödünçlemelerin Türkçe kökenli olanlarının ilk sözlük birimi şekli ve anlamlarının dışındaki anlam kayması örnekleri üzerinde durulmaktadır. Belli başlı iki kaynak (Balkan Dillerindeki Türkçe Kültür Kelimeleri ve Türkçe Verintiler Sözlügü) verilerinden hareketle tarama yoluyla tespit edilen sözcüklerdeki anlam farklılıkları Türkçe Sözlük'ün 1988 ve 2011 yılı baskılarındaki madde başlarıyla karşılaştırılarak anlam farkl1lıkları tespit edilmiştir. Balkan Dillerindeki Türkçe Kültür Kelimeleri adlı çalışmada 1988 basımı Türkçe Sözlük esas alınmıştır; sözcüklerin bir kez daha

\footnotetext{
${ }^{3}$ G. Stern "dış değişme" veya "dil dışı değişme"; Ulmann ise "dilin muhafazakârlığından doğan değişmeler" terimlerini kullanmıştır (Şahru 2019: 144).
} 
kontrol edilmesi amacıyla da 2011 basımı Türkçe Sözlük tekrar gözden geçirilmiştir. Türkçe Sözlük'ün her iki baskısında bulunmayan, çok daha eski tarihlerde Türkçeden Romenceye giren Türkçe sözcükler ise bu konuda hazırlanmış tarihî sözlükler kullanılarak değerlendirilmişlerdir. Nihayet, bu konuda en kapsamlı çalışmalardan biri olan Türkçe Verintiler Sözlüğ̈̈'nün Romence ile ilgili olan madde başları da değerlendirilmiş ve güncel bilgilerle veriler zenginleştirilmiştir. Makalenin basım boyutu göz önünde tutularak Türkçe Sözlük'teki madde başı açıklamalarının tümü değil; sadece Türkçe sözcüklerin Romenceye girdiği ilk sözlük birimi şekli ve anlamı ve bu anlamın dışında kazandığı yeni anlamlar değerlendirilmiştir.

Türkçeden Romenceye geçen sözcüklerin ilk kabul gören anlamları, genellikle Türkçedeki bilinen sözlük anlamlarıyla benzerlik göstermektedir; zaman içinde ise bu anlamlar farklı anlam boyutlarına sıçramışlar, kimi sözcükler ise yeni mecaz anlamlar kazanarak deyimleşmişler ve günlük dile sirayet etmişlerdir.

Alfabetik olarak sıraladığımız sözcüklerde sözcüğün Türkçe Sözlük'teki bilinen anlamının dışında Romencede kazandığı yeni anlamlar, deyimlerde geçen anlamları ve anlam kayması örnekleri şunlardır:

\section{Bulgular}

ağa > Rom. agă, agha, agia "bey, beyefendi; başkan, yönetici; eski zamanlarda güvenlik görevlisine verilen ad"; adžie, agacie, agie "polis"; adžesk, agesk "polislik" (Mik. 6; Şay. II, 11; Lok. 28; Kak. 29; Wendt. 130, 132, 150; Rol. 63).

ağırlık > Rom. agărlîc, agărlăc, angărlîc, aglomerat "kalabalık" (Mik. 6; Lok. 31; Kak. 29).

alışveriş > Rom. a face alişveriş "iyi bir şey yapmak yerine her şeyi birbirine karıştırmak" (Mik. 10; Lok. 63; Rol. 65).

altın > Rom. altângic, altîngic, altanîc, altângea, altâgic "bir tür dereotu; krizantem çiçeği; lale" (Mey, 8; Lok. 61; Kak. 38).

ana > Rom. anasâna, a lucă/lucra a aduce cu anasána "anasılyla almak, zorla almak: bir kişiyi istemediği bir şeye zorlamak" (DP).

Anadolu > Rom. anadol "bir çeşit kürk manto" (Lok. 76; Mik. 11)

az- > Rom. jazme "nefret, tiksinme" (Mik. 1884, s. 16)

bağır > Rom. baiera "iç organlar; elbise askısı, kemer çeşidi"; beregată "boğaz, bağırtlak" (Lok. 174, 326).

bağırsak > Rom. băere "bir kemer çeşidi" (Lok. 174).

bağlama > Rom. balama, balamale "reze, zıvana, bağlama, kapı veya pencere menteşesi"; a-şi ieşi din balamele, a scota din balamele "zıvanadan çıkmak: çok öfkelenmek"; a-i tremura balamele "titremek: kaygılanmak" (Mik. 17; Lok. 173; Rol. 69). 
bahadır > Rom. bater "güreşçi, sporcu"; bahadîrcă "işveli ve cilveli kadın; yaşlı ve cilveli kadın" (Mik. 18; Lok. 16, 175; TMEN 817; DP).

bal > Rom. balmoş "buğdaylı pişmiş süt kaymağı"; balbaş, babaş "ballı su" (Mik. 19; Lok. 201).

baraka > Rom. bărk "su deposu, sarnıç" (Rol. 72).

bardak > Rom. bardac, bărdacă "kap, testi; mürekkep hokkası; bir erik türü"; bărdăcută "küçük kap" (Mik. 20; Lok. 230; Rol. 73).

basırgan "yağmacı, çapulcu" (EDPT) > Rom. bosorcáie "hayalet; cadı, büyücü; uyurgezer"; a bosconi "büyü, büyüleme" (MTESz, I, 351; Bak. 322).

basma > Rom. basma "mendil"; a ieşi (scăpa) basma curată "temiz basma çıkarmak: güçlükten sıyrılmak"; a-l scoate (pe cineva) basma curatá "birinin basmasını temizlemek: birini suçtan kurtarmak, temize çıkarmak" (Mik. 21; Lok. 264; TMEN 695; Rol. 73).

başıbozuk > Rom. başibuzuc, başbuzuc "kötü kişi" (Lok. 266; TMEN 704).

başka > Rom. başca "başkalui, başkui "ayırmak, uzaklaştırmak"; basca "adam baş giysisi, başl1k" (Mik. 22; Lok. 263; Rol. 74).

beş, beşli, beşlik > Rom. beşliŭ, beşlîc "beş liralık; beş kişiden oluşan, eski bir atlı asker birliği"; beşléga, besleagă "beşli ağası; yaşlı, bunak"; beşactea "beştahta; mücevher kutusu" (Şay. II, 48; Kak. 70; Rol. 77).

bızdık > Rom. a-i sări (cuiva) bîzdîcul "bızdığı sıçramak: darılmak, küsmek, her şey toz pembe iken bir anda kızmak, birden parlamak" (DP)

bike "Zengin kadın, bey hanımı" (TTAS) > Rom. bechéş "prenses elbisesi, kışlık kisa palto, kürk" (MTESz, I, 221).

binici > Rom. binigiŭ "ahır hizmetçisi, seyis" (Lok. 308; TMEN 1750).

biniş > Rom. biniş, binişel "subay elbisesi, üniforma; takım elbisenin bir parçası; elbise"; binişliŭ "biniş giyen; zengin" (Mik. 28; Lok. 308).

bitirme > Rom. beterme, betermea, biterme "muvafakiyet, anlaşma, müttefikan verilen karar; çözüm" (Mik. 29; Lok. 317).

boğa > Rom. buhai, buhaŭŭ, bagea "koç; büyük manivela, kaldıraç" (Mik. 31; Lok. 339; TMEn 752; Bak. 209).

bohça > Rom. bocceà, bogceà, bohcea, bohgea, botšalék "kumaş paket; balya, denk; dört köşeli şal; önlük; tütün paketi"; boccealîc, boccealâc "baş örtüsü"; boccealic "elbiseden oluşan hediye"; bordžalék "uzun beyaz önlük" (Mik. 28; Şay._III, 54; Mey. 40; Lok. 325; Kak. 75).

bok > Rom. bocciŭ "çirkin, kötü, pis; kaba, pek sosyal olmayan kimse" (DP).

bokluk > Rom. bocluc, bucluc "sıkıntı, güçlük, dert, bela, problem"; buclucgiŭ, buclucaş "kötü, kötülük yapan; geveze, boşboğaz; bok herif"; a da de bucluc "bokluğa çatmak: belaya düşmek" (Lok. 329; TMEN 800; Rol. 79). 
boran > Rom. borantă "su burgac1, anafor" (Lok. 13).

borazan: (T. + Far.) > Rom. bolozá, bolozán, borozán, burazan "büyük kayık, gemi; büyük dünya yuvarlağı" (Şay. II, 57; Kak. 77).

boru > Rom. buriŭ "küp, fiçı" (DP).

boz > Rom. múrgă "koyu renkli, yağız tenli, koyu tüylü" (Bak. 267; GK).

budak > Rom butuc "kütük, kök; tekerlek göbeği; sap"; budác "dikim çapası, bask1"; a dormi butuc "kütük gibi uyumak"; a lega (pe cineval) butuc "kütük gibi sıkıca bağlamak"; a trage (cuiva) butucul "kütük çekmek: aldatmak"; a sta ca un butuc "kütük gibi hareketsiz durmak" (TMEN 779; Bak. 228, 323).

Bulgar, bulgari > Rom. bulgariŭ "sağlam ve yumuşak deri, telatin" (Şay. III, 23; Lok. 351; TMEN 766; Kak. 82).

bulgur > Rom. bulgăr, bulgăre, bulguri "kesek, çift sürerken oluşan tezek; top, yuvarlak nesne; bulgar; kar topu"; bulgár de zăpadă "kartopu" (Mik. 33; Şay. II, 61; Lok. 352; Kak. 82; TMEN 736; Rol. 83).

burduk "tulum, su kabı" (KTTS) > Rom. burdúf, burdúh, burdúv "karın, gövek; kuyu, oyuk" (Bak. 210, 286; GK).

burma > Rom. burma "devir; vida" (Lok. 227).

but > Rom. butură "ağaç kütüğü, büyük kereste"; buturugă "kırık veya kesik parça" (Mik. 31; Lok. 30, 372; Wendt. 152).

bükme > Rom. buclŭ "saç lülesi, zülüf"; bucluc "dolaşık, karışık"; bucmea "bükme ip, şerit, kaytan" (Mik. 31).

caba > Rom. degeabă "nafile, boş yere, boşuna" (Mik. 53; Lok. 625).

car > Rom. gear "şal, Hint şalı" (Lok. 668).

carla- > Rom. ciripe, ciripire "cırlama, kuş ötüşü, cıvıltı" (Lok. 450).

cırcır > Rom. ciripit "ötüş"; ciripire "ötmek, ötüşmek" (Lok. 450).

çabata "ihlamur ağacından elde edilen iplerden örülmüş pabuçlar" (TTAS) > Rom. çabata, ciubotă, ciobotă "çizme, uzun konçlu ayakkabı" (Lok. 379; ML. 2448).

çakan 'topuz, tokmak, çekiç' (TTAS). > Rom. ciocán "kazma" (Bak. 289).

çakır > Rom. ceacar, ciacăr, čjaker "şaşı; aşağılama sözü"; ciorcîlie "çakırdoğan"; ciocîrlan, ciocîrlie "tarla kuşu, çayır kuşu"; a prinde ciorcîrlanul de coadă "sarhoş etmek" (Mik. 35; Lok. 386; Şay. III, 142; Kak. 98; TMEN 1090).

çam > Rom. ceam "çam ağacından yapılan büyük gemi" (Lok. 389).

çaワ > Rom. cinhhie "harp, müzik aleti" (Mey. 444; TMEN 1128).

çanta > Rom. geantă "fişeklik"; gentulită "küçük çanta" (Mik. 36; Lok. 393; TMEN 1053). 
çapan "parçalı giysi, cepken, palto, kaftan" (TTAS, KTTS) > Rom. şabana "memur elbisesi, cepken" (Wendt. 91).

çapkın > Rom. ceapcîn "tırıs yürüyüşlü at; kurnaz, açıkgöz; hileci, hilekar; çapulcu, soyguncu" (Lok. 394; TMEN 1036).

çaprak > Rom. cepregar "at koşumcusu, saraç" (Mik. 36; Lok. 396).

çarık > Rom. cioarec, cioareč̆ "beyaz, yünlü köylü pantolonu" (Mik. 37; Lok. 401; TMEN 1044).

çatı > Rom. cetlau "bağ, ilmik; koşum takımı; arabanın üzerini örten çapraz sirıklar" (MTESZ. I, 484).

çatma> Rom. čétmá "bir tür ipek" (TMEN 1049).

çat pat > Rom. ceac-pac, ceat-pat "sırasında, yeri geldikçe; ara sıra"; tac-pac "çok çabuk" (Lok. 403; DP).

çavuş > Rom ceăuş, ceauş, ciaús "kapıcı; karakol görevlisi; resmî daire katibi; çavuş üzümü" (Mik. 38; Şay. II 25; III, 40; Lok. 404; Kak. 101; TMEN 1055; Rol. 91).

çek- > Rom. cărăbăni "çek arabanı!; gitmek"; a se cărábáni "gizlice gitmek, terketmek" (Mik. 12 Lok. 90; Kak. 41; Wendt. 35; Rol. 66).

çekme > Rom. cecmea "bir tür kumaş; örtü, yaşmak" (Wendt. 103; TMEN 1104).

çelebi > Rom. celebiü, cilibiŭ "züppe" (Mik. 39; Şay. II, 100; Lok. 407; Kak. 103; TMEN 1112).

çerçi > Rom. cercel "küpe"; cercelar "küpe yapan veya satan kişi; çerçi, ev ev dolaşan satıcı" (Lok. 410; Wendt. 138; TMEN 1075).

çerge > Rom. cergă, čerge "yüklük, yüklük örtüsü, köy halısı; araba örtüsü; örtü; kalın dokuma, keçe, bıranda bezi" (Mik. 40; Lok. 412; Bak. 208).

çıkın > Rom. ciochină "demet, deste"; ciorchine "salkım"; ciorchine de struguri "üzüm salkımı"; ca pune (a atîrna) a lega (a spînzura) ceva la ciochină "çıkınlayıp asmak: unutmak" (Lok. 449; DP).

çıkıntı > Rom. ciochină "eyerin ön kaşı" (Lok. 449).

çırpı > Rom. ciripie "ölçü şeridi, mesura; doğru, düz çizgi, hat; yapı ustasının kullandığı ip"; a merge a trage ca pe ciripie "dosdoğru gitmek" (Lok. 450).

çivit > Rom. civit "karbon kağıdı" (Mik. 42; Lok. 429).

çortan "tatlı suda yaşayan yassı başlı, uzun gövdeli, ördek burunlu bir tür balık" (TTAS) > Rom. ciortan "iri sazan balığ1; tavuk butu"; ciortănaş "küçük tavuk butu" (DP).

çöl > Rom. giol "aşık oyununda eldeki aşıkların toplamı"; a face, a da pui de giol "tüm aşıkları ütmek" (Wendt. 104). 
çubuk > Rom. ciubuc "pipo çubuğu; pervaz, korniş; bahşiş, rüşvet"; a fi ciubucar "çubuk gibi yanmak: aşık olmak"; a da ciubuc "çubuk vermek: bahşiş vermek; rüşvet vermek"; a lua ciubuc "çubuk almak: bahşiş almak; rüşvet almak"; ciubucciu, ciubukgiŭ "çubukçu; pipo içen"; ciubeică "bahşişlik"; ciubucar "bahşiş veren; rüşvetçi"; ciubucárie "rüşvetçilik" (Mik. 43; Lok. 447; TMEN 1059; Rol. 97).

çukur > Rom. ciucurluc "bir kemer biçimi" (DP).

çürük >Rom. ciurúc "değersiz; kullanılmış, eski; ayaktakımı, serseri, külhanbeyi" (Şay. II, 139; Lok. 446; TMEN 1078; Kak. 114).

dal- > Rom. talmeş başmeş "karmakarışık, çok karışık"; a face talmeş "karıştırmak, dala bata veya bata çıka yürümek" (Lok. 201).

dalak > Rom. dalak, delak, dalac "veba kabarcığı, veba; dalak iltihabı, kızıl yara, şirpençe; cerahatli sivilce; bir bitki" (Mik. 45; Lok. 469).

damla > Rom. dambla, damla "damla hastalığı, beyin kanaması"; damblagiŭ, damblaliǔ "damlacı"; a-l apuca damblaua "damlası tutmak: çok kızmak, öfkelenmek"; a-i face cuiva damblaua "delice istediğini yapmak" (Mik. 45; Lok. 79).

değirmen > Rom. a terece prin ciur şi dîrmon "değirmenden geçirmek: elemek, eleştirmek; dedikodu yapmak; incelemek" (DP)

deli > Rom. deli, diliŭ, deliŭ "cesur, yürekli, yiğit; yakışıkli; hassa karakolundaki asker"; deli başă "deli başı, elli askerli birliğin başı" (Mik. 46; Şay. II, 155; Lok. 506; TMEN 1008; Kak. 121; Bak. 311; Rol. 99).

delişmen > Rom. tălăşman "huysuz" (Şay. II, 155; TMEN 1008; Bak. 311; Rol. 99).

demir > Rom. dimircapi "dağ geçidi" (Wendt. 79).

demirli > Rom. demerlie, dimirlie, dimerlie "tahıl yığını, hububat yı̆̆ını; eski bir tahıl ölçeği; öğütme karşılığı değirmenciye verilen miktar"; (Mik. 46; Wendt. 79; Kak. 121).

denk > Rom. teanc "paket, demet"; tenculet "paketçik" (Mik. 46; Lok. 484; Wendt. 112; TMEN 941; Rol. 88).

dibek > Rom. durbác "tahta fiçı, varil" (Meyer, 78)

dikiş > Rom. dichiş "teferruat; donanım, süs; kadınların süslenme işi" (Lok. 517).

direk > Rom. dric, derec, direg "araba oku"; direchie "direkli yap1, kemer, revak"; direklie, dereglie "direkli gemi"; dric "tabut" (Mik. 48; Lok. 522; TMEN 997, 998; Kak. 126; DP).

dol- > Rom. doldora, doldora de bani "zenginleşmek, zengin olmak" (Lok. 531).

dolma > Rom. dulme "bir cins kabak" (Mik. 50). 
dolu > Rom. a fi doldora de bani "zenginleşmek, çok parası olmak" (Lok. 531; Wendt. 120, 121).

dönüm > Rom. dunium "yığın, küme; kalabalık" (Lok. 528).

düğün > Rom. duium "topluluk, kalabalık; yığın"; cu duiumul "kalabalıkta, topluluk içinde" (Lok. 528; Wendt. 181).

düvlek "olmamış ham kavun; kelek" (OTS) Rom. dovleác "kabak"; dovlecel "su kabağı" (Lok. 555; Wendt. 80; Bak. 292; Rol. 104).

düz $>$ Rom. tiz "isimleri aynı olanlar" (Mik. 52).

eğlence > Rom. eglinge, eglindi, elgindi "istirahat, dinlenme, mola, teneffüs" (Lok. 560)

elma > Rom. alma "doğranmış pırasa" (Lok. 562).

erdem > Rom. ardamalasc "değer; fiyat, ücret" (TMEN 451).

gecelik > Rom. ghigilic, ghigelic "gece takkesi" (Lok. 704).

germe > Rom. ghermec "araba tekerlerlerine konulan çapraz tahta, gergi" (Wendt. $56,57)$.

gidi > Rom. ghidi "bak sen!"; ghidi ghidi hot bătrăn "seni gidi moruk seni!"; ghiduş "şakacı, cambaz"; ghiduşie, ghiduşesc "maskaralık, soytarılık, dolandırıcılık" (Mik. 12; Şay. II. 181; Lok. 718; Wendt. 10, 16; Kak. 160).

göç > Rom. ghioci "at arabası" (Lok. 725).

göden > Rom. ghiuden, giuden "sucuk; yassı şekilde preslenmiş kuru sucuk; kurutulmuş yiyecek" (Mik. 13; Lok. 726; Rol. 111).

hayda- > Rom. haidamac "gezgin, gezici, göçebe" (Lok. 780; ML 3994; Wendt. 122; Rol. 118).

hırsız > Rom. hursuz, ursuz "ters, aksi; dost olmayan; sert, haşin" (Lok. 1927, nr. 891).

iki > Rom. ichŭu "ikili, tavlada zarın iki gelmesi"; ichilik "eski bir ağırlık ölçüsü" (Lok. 900; Wendt. 104, 105).

ikindi > Rom. chindíe "eğlence; doğum günü; kutlama"; diseară avem chindie la un prieten "bu akşam arkadaşta eğleneceğiz" (Mik. 75; Şay. II, 113; Lok. 901; TMEN 650; Kak. 193).

İstanbulin > Rom. stamboală "kiler, depo"; cu stamboală "çok" (DP).

kabuk > Rom. kulbek "sümüklü böcek, salyangoz" (Mik. 84).

kaçırma > Rom. cacealma "poker oyununda elini iyi göstererek rakibi kaçırma" (Rol. 125; DP).

kadın > Rom. cadîna, cadînă "Müslüman kadını; güzel, çekici; sevgili" (Mey. 164; Lok. 989; Wendt. 152; TMEN 1159; Rol. 126). 
kaftan > Rom. a îmbrăca pe cineva în cu caftan "kaftan giydirmek: soyluluk unvanı vermek"; a lua un caftan "dayak yemek" (Mik. 85; Şay. II, 73; Lok. 774; TMEN 1168; Kak. 206; Rol. 127).

kalabalık > Rom. calabalic c "bagaj, yük, eşya; kargaşa, gürültü, şamata, patırtı"; cu tot calabalăcul "bütün yüküyle birlikte" (Mik. 87; Lok. 645; Kak. 209; Bak. 298; Rol. 127).

kalık > Rom. calîc "sakat adam, kötürüm; yoksul, sefil, fukara; miskin"; călăciă "kötürümlük, sakatlık; sefalet, yoksulluk, fukaralık" (Lok. 1040).

kapak > Rom. a găsi capac la toate "her şeye kapak bulmak: her şeye cevap yetiştirmek"; a pune (cuiva) capac "uygun cevapla ağzını kapamak"; asta pune capac "bir bu eksikti!"; ouă la capac "sahanda yumurta" (Lok. 1061; TMEN 1367, 1422).

kaplama > Rom. căptuşeala "astar, kaplama"; căplămă "bir çeşit giysi"; căptuši "astarlamak" (Mik. 90; Lok. 1065).

kaplan > Rom. caplàn "bir çeşit Türk asker sınıfi" (Şay. III, 28; Kak. 217).

karabaş > Rom. cărăbuş "mayıs böceği, bok böceği" (Mik. 91).

Karagöz > Rom. caragios, caraghios, caraghiòz "kukla oyunu; soytar1; deli; eğlendirici kimse; kukla"; caraghioslîc, caraughioslâc "şaka, soytarılık, Şaklabanlık"; a fi caraghios "karagöz olmak: gülünç duruma düşmek" (Mik. 74; Şay. II, 88; Lok 1079; Wendt. 152; Kak. 220; Rol. 132).

karakol > Rom. caraulă, caraúl "nöbetçi; bekçi; nöbetçi asker" (Mik. 91; Lok. 1078; Wendt. 102, 156; TMEN 276; Kak. 222; Rol. 132).

karaman > Rom. caraman "kara inek veya manda"; caramangiŭ "kara sığır yetiştiren" (Şay. II, 396; Kak. 222).

kavuk > Rom. cauc "kadife şapka, zengin şapkası" (Mik. 94; Şay. II, 96; Mey. 183; Lok. 1137; Kak. 228).

kaytan > Rom. a merge găitan "işlerin yolunda gitmesi" (Mik. 86; Ney. 117; Şay. II, 176; Lok. 644; Wendt. 16; TMEN 1605; Kak. 231; Bak. 214; Rol. 136).

kazak > Rom. kazak, cazacă "yol kesen haydut; serseri"; cazacliŭ "haydut" (Mik. 94; Lok. 1143; Wendt. 103).

kebe > Rom. chebă, ghebă, kebe "kaban, manto, yünlü kalın dokumadan yapılmış palto" (Mik. 5; Lok. 971; Bak. 334; Rol. 137).

kefe > Rom. kelfănez "firçalamak"; chelfăni "dövmek"; chelfáneală "kavga" (Mik. 5; Lok. 995).

kelepir > Rom. chilipir, kilipir "kazançlı alış veriş"; chilipirgiŭ "alış verişte şanslı olan; şanslı, talihli" (Mik. 5; Mey. 221; Lok. 1156; Rol. 138).

kepenek > Rom. chepeneag "manto, palto" (Mik. 6; Lok. 1159; TMEN 1617). 
kılavuz > Rom. călăuză "yönetici"; călugăr "Ortodoks rahip" (Mik. 95; Şay. II, 80; Mey. 169; Lok. 1276; TMEN 1504; Kak. 237; Bak. 297; Rol. 140).

kır- > Rom. curma "kesmek ayırmak; bölmek; bir şeye ara vermek"; precurm "kesmek"; curmej "parça, kısım, adet" (Mik. 96; Lok. 1278).

kırp- > Rom. cîrpáci "yamac1, yama yapan terzi; sahtekar"; a cîrpáci, a cîrpi "yamamak, yenilemek" (Bak. 338).

kışla > Rom. câşla "küçük baş hayvan ağılı"; câş̧larie "çiftlik"; chişleac "kışlık, köy" (Şay. II, 117; Lok. 1281; Wendt. 136; TMEN 1496; Kak. 239).

koca > Rom. coşcogea "eksiksiz, tam, mükemmel" (Wendt. 123).

kolçak > Rom. colceac, kolceag "kılıf, kovan, kola geçirilen eğreti kolluk; önü bağcıklı bir ayakkabı türü" (Mik. 98; Lok. 1196).

kolt- "söylemek, isteği söylemek; istemek, aramak" (EDPT; GK) > Rom. a colindá, a corindá "bozuk bir sesle şarkı mırıldanmak; dinî bayramda dinî şarkı ve dualar söyleyerek evden eve dolaşmak; dilenmek" (Bak. 261; GK).

koltuk > Rom. coltuc, kultuk "dirseklik, baş yastı̆ğ, yer minderi; yaşlı, ihtiyar; ekmek dilimi" (Mik. 98; Lok. 1199; TMEN 1575; Rol. 143; DP).

konak > Rom. conac "otel, han; durak; lokanta; postane"; conăcar, conacărie, conacciŭ "otel veya lokanta sahibi" (Mik. 98; Şay. II, 142, 144; Lok. 1202; TMEN 1539; Kak. 246).

kopuz > Rom. cobuz, cobză "mandolin; küçük çoban kavalı"; konzé "kanuna benzer bir çalg1" (Mik. 9; Lok. 1206; Wendt. 78, 157; TMEN 1546; Bak. 340).

korucu > Rom. curugiŭ "emekli asker" (Mik. 99; Kak. 246).

kotan > Rom. cătun, cotuna "küçük köy" (DP)

kova > Rom. cofă "ölçek, ölçü, mikyas"; covată "hamur teknesi"; covătea, covătică "teknecik" (Mik. 97; Mey. 203; Lok. 1225).

kör > Rom. chior "tek gözlü"; khiorîş "şaşıllk"; a da chior (peste cineva) "kör gibi yaklaşmak: çarpışmak"; a lua de-a chioară "kör kör dolaşmak: aptalca gezinmek"; a se uita (privi) chiorîş "düşmanca bakmak"; a nu avea (nici o) para chioră "kör kuruşu olmamak"; a da chiorîş (prin ceva) "kör gibi atılmak"; chiorîş̧ "gizli; gizlice"; a privi chioriş "gizlice bakmak" (Mik. 9; Şay. II, 114; Lok. 1207; Kak. 249; Rol. 144).

köstek > Rom. chictoc, ciostec "tuşak; atın ayağına vurulan zincir; izmarit" (Mik. 10; Mey. 229; Lok. 1211; Wendt. 11).

kul > Rom. cul "hizmetçi; asker"; culoglu "piyade askeri" (Mik. 100; Şay. III, 143; Lok. 1239; TMEN 1579, 1580; Kak. 251).

kutu > Rom. scos din cutie "kutudan çıkmış: zarif"; bagă capul la cutie "başını kutuya sokmak: omzunu kısmak" (Mik. 102; Şay. II, 151; Lok. 1121, 1271; Wendt. 153; TMEN 1569; Kak. 257; Rol. 147). 
lök > Rom. lichium, likjum, luchium, ludyum, lukjum, "kuyu yapımında kullanılan bir çeşit çimento, inşaat harcı" (Mik. 17; Lok. 1328).

malak > Rom. malac "kaba, iri, biçimsiz" (DP).

mor > Rom. mormaviŭ "açık kırmızı ya da kırmızıya çalan renk" (Lok. 1482); meriŭ, merliŭ, mieriŭ "gök mavisi"; marmaziŭ "mor menekşeye benzeyen renk" (Mik. 27).

obruk /(opra-?)> Rom. obrêg "bol kadın giysisi, ferace" (Bak. 305).

oda > Rom. odaie, hodáie, odae "ağıl, ahır; ortak çiftlik, kooperatif çiftliği; aile, yuva; yeniçeri kışlası"; oda-lalasi "oda müfettişi"; odăiaş "küçük odada kalan kişi" (Mik. 24; Şay. II, 274; Mey. 314; Lok. 1584; Kak. 307; Bak. 296; Rol. 164).

oğlan > Rom ulan "hafif silahlı süvari, atlı asker" (Lok. 1588; TMEN 498).

orçuk > Rom. orciúc, orşic, orcíc "koşum aleti, araba oku" (Bak. 304; GK).

ordu > Rom. orda, oarda, ordie, urdie "konaklama yeri, kamp" (Mik. 35; Şay. II, 91, 373; Lok. 1594; Kak. 309).

orta > Rom. orta "meydan; alay; kıta, müfreze, birlik"; orta-ciauş "orta çavuşu" (Mey. 316; Lok. 1597; Kak. 310).

otă̆, otak > Rom. otac "hayvan barınağı, ağıl"; odaie "oda" (Lok. 1599; Wendt. 51, 52, 53, 137; TMEN 489).

oturak > Rom. oturác "emekli asker; savaş malulü asker" (Şay. III, 92; Kak. 313).

otuz > Rom. otuzbir "otuzbir, bir iskambil oyunu; zor, şiddet"; a juca otuzbirul "otuzbir oynamak"; cu otuzbirul "zorla"; a lua cu otuzbirul "zorla almak" (Lok. 1600).

oylum > Rom. olum "ağıl çiti; ağıl' (DP).

oyun > Rom. oínă, hoínă "bir çeşit beyzbol oyunu" (Wendt. 157).

ör > Rom. uríc "miras, kalıt" (MTESz. III, 36).

parmak > Rom. palmac "baş parmak" (Lok. 1636; Wendt. 159; Rol. 168).

parmaklik > Rom. parmac "direk, kazık"; parmaclîc, parmalîc "çit"; parmak; parmaklîk "rampa" (Mik. 38; Lok. 1636; Wendt. 159; Rol. 168).

pastırma > Rom. a face pastramă "birini pastırma yapmak: çok dövmek"; a se face pastramă pe cineva "pastırması çıkmak: zayıf düşmek" (Mik. 38; Şay. II, 285; Mey. 323; Wendt. 124; Kak. 320; Bak. 305; Rol. 169).

sağrı > Rom. sagry "deri iplik" (ML 7513).

salkım > Rom. salcîm "akasya ağacı" (Mik. 49; Lok. 1809; Wendt. 9, 15)

saya > Rom. saia, saiac, saielutsa "saya, kalın yünlü kumaş"; saiagiŭ "çoban"; sagesc, saigie, saigit "yünlü kumaş yapan kişi" (Şay. II, 397; Lok. 1778, 1779; Wendt. 110; Kak. 354). 
sayı > Rom. sameş "sayıcı, para sayan, vezne idarecisi; muhasebeci" (Lok. 1821; TMEN 1219).

sıra > Rom. şiră "bel kemiği, omurga" (Mey. 382; Lok. 1961).

sik > Rom. sîc, sictír "boş ver, iyi oldu"; a da cuiva cu sîc "kızdırmak, çileden çıkarmak"; sâcâi, sîcai "hiç bir şey beğenmeyen, züppe şımarık"; a-i da cuiva cu sictir "sövmek"; sictirecs "kovulan"; sictirit "kovma" (Lok. 1960; TMEN 1314; Rol. 183).

sokman > Rom. sucman, suman "kaftan, bol giysi, tulum, kaban, kalın çuha kumaştan yapılan palto" (Lok. 406; Wendt. 59, 60; TMEN 1297; Bak. 221).

subaşı > Rom. subaşă "en yaşlı köylü, köyün en yaşlı kişisi" (Şay. III, 111; Mey. 395; TMEN 1279; Kak. 371).

sundurma > Rom. șandrama "tahta baraka; kırık dökük eşya" (Lok. 1927, nr. 1948); șăndrama "aynı" (Meyer, G. 1891, s. 396; Mik. 1888, 57).

su yolcu > Rom. sujuldžiŭ "su kuyusu ustası" (Mik. 58).

şaşkın > Rom. şaşcânlîc "düşüncesizlik" (Şay. III, 162; Kak. 381).

şimdi > Rom. pe şin "âni, derhal, çabucak" (Mik. 64).

taban > Rom. taban "ayak tabanı; ayakkabı altına çakılan demir; uzun ve ince tahta; döşeme tahtası, çıta; iyi cins demir"(Mik. 65; Lok. 1963).

tabur > Rom. tabără "yığın, sürü; kamp; tatil köyü"; tăbări "üstüne gitmek, yığılmak"; tăbărên, tăbărean "kampta bulunan kişi" (Mik. 66; Lok. 1974; TMEN 2055).

takım > Rom. tacîm, tacâm "at koşumu; topluluk, grup; külhanbeyi takımı; herif, fahişe"; un tacăm de neajunsuri "olumsuzluklar takımı" (Mik. 66; Mey. 422; Lok. 2000; Rol. 191).

takla, taklak > Rom. taclale "yuvarlanma"; a sta (a se pune) la taclale "taklaya oturmak: sohbete dalmak" (Rol. 192).

talan > Rom. talan "kan çıbanı, kızıl yara" (DP).

tansuk > Rom. tensuf "kokulu tohum" (TMEN 939).

tarım > Rom. tărim "yer, masalsı bir yer"; tărim de vis "rüya gibi bir yer" (Lok. 2039; Wendt. 111, 112).

tas > Rom. tas, teas "su kab1; kurna, leğen"; a umbla cu tasul "dilenmek" (Mik. 69; Lok. 93, 2044; Wendt. 93; Rol. 194).

tasma > Rom. tasma "şerit, şapka şeridi; kan alma bağı; boyun süsü"; tăsmălută "küçük süs, şeritçik" (Mik. 69; Lok. 2043; Wendt. 94; Rol. 194).

Tatar > Rom. tătăr, tătar "haberci, kurye"; tărtăcuşa "ak buğday; yuvarlak kabak"; tatar "tatar atı"; tătarıă "tatar kısrağ1; kürk manto"; doar nu vin dau tătarii "arkandan Tatar mı geliyor!"; tătarcă "tatarca"; tătăraş "tatar yavrusu"; tătăresc "tatarlık"; tătăreşte "tatarca"; tătărime "tatarlar"; tatarită "küçük tatar 
kızı"; tătăroaică "yaşlı tatar kadın"; tătăroi "yaşlı tatar" (Mik. 69; Şay. II, 351; Lok. 2045; TMEN 850; Kak. 387).

teker > Rom. techer-mecher "hemen, derhal, şimdi; çabucak; ansızın, birdenbire" (Lok. 2059)b

tekne > Rom. tejke "kova"; teică "değirmen teknesi; gırtlak" (Mik. 71; Bak. 221).

teneke > Rom. tinichea "sıvı kabı, maşraba; gaz tenekesi, bidon"; tinichelută "küçük kova"; a ajunge la tinichea "tenekeye dönmek: çok sarhoş olmak"; $a-i$ pune (a-i lega) cuiva tinecheaua "kuyruğuna teneke bağlamak: sürekli rahatsız etmek"; a lăşa (pe cineva) tinichea "tenekeye benzetmek: yoksul düşürmek"; a fi (a rămâne) tinichea "parasız kalmak" (Mik. 72; Mey. 426; Lok. 2065; Bak. 368; Rol. 197).

teyel > Rom. tighel "kumaş kenarlarındaki dikiş; yorgan dikişi"; a trage cuiva un tighel "birine teyel çekmek: çıkışmak, haddini bildirmek, azarlamak, paylamak"; tighelecs "teyelci"; tighelcală "teyelcilik, terzilik" (Lok. 2058).

titiz > Rom. tuiş "tuhaf" (Mik. 75).

toklu > Rom. tulŭc "genç sığır" (MTESz. III, 1000).

tombaz > Rom. dudas, dombàz, tumbaz "feribot, araba vapuru" (Mik. 76; Kak. 398).

topal > Rom. tăpălágă "biçimsiz yürüyüşlü, çarpık yürüyüşlü" (Bak. 311; GK).

topuz > Rom. cu topuzul "topuzla: zorla, güç kullanarak"; a lua cu topuzul "topuzla alma: zorla almak" (Mik. 76; Lok. 2090; TMEN 1348; Kak. 400).

torlak > Rom. turlac "şarap; şaraplı, sarhoş; düşüncesiz; yabanî; palavracı"; turlăsesc "tembel, palavracı" (Mik. 76; Şay. II, 369; Mey. 433; Lok. 2092; Kak. 401).

torluk > Rom. turluc "kömür ocağı" (Lok. 2093).

tortu > Rom. turtă "şarap tortusu"; a fi turtă "tortu olmak: çok sarhoş olmak"; $a$ coace cuiva turtă "tortu pişirmek: tuzak kurmak"; a face turtă "tortu yapmak: kötü dövmek"; a trage cenuşa pe turtă "külü tortusuna çekmek: çıkarını düşünmek" (Mik. 77; Bak. 370).

toy > Rom. toi, toj, toŭ $\breve{u}$ "zirve, doruk; bolluk, çokluk; en parlak kısım; kalabalık; sürü"; în toiul luptei "savaşın doruğunda"; toi "bağırmak, gürültü yapmak" (Mik. 75; Lok. 131, 2086; TMEN 1352).

Türk > Rom. turc "Türkçe"; a fi turc "Türk olmak: inatçı ve kararlı olmak; söz dinlememek" (Lok. 2114).

uğur > Rom. ogur "tahmin, kehanet; kestirme"; ursuzenie "rahatsılık vermek" (Mik. 80; Lok. 891, 1589; TMEN 604; Rol. 204).

ulak > Rom. olac "acele posta, hızlı posta; yedek at, posta atı"; olăcar "atlı postacı, hızlı özel posta"; cal de olac "ulak atı gibi: çok çalışma, aşırı çaba"; $c u$ cai de olac "ulak atı ile: çabuk, acele"; a lua pe cineva de olac "ulak tutmak: acele 
etmek"; olăcar "aceleci, hızlı"; olăcărie, olăceşte "acele eden kimse" (Mik. 80; Lok. 2130; Wendt. 88; TMEN 521).

vergi > Rom. a da bir cu fugitii "kaçaklara vergi vermek: kaçmak, gözden kaybolmak, sıvışmak" (DP).

vur- > Rom. urdubelea "beklemedik, umulmadık; beklenmedik sıkıntı" (Lok. 2167).

yabancı > Rom. ̌̆abangiŭ "çok gezen; haylaz, tembel; serseri" (Mey. 160; Lok. 921).

yaka > Rom. a pune cuiva iacaua "yaka koymak: yalvarmak"; a feşteli iacaua "yakasını ezmek: gülünç duruma sokmak" (Mik. 78; Lok. 927; TMEN 1802; Rol. 207).

yapıncak > Rom. ipingea, iapingea "yağmurluk, palto" (Mik. 79; Mey. 163; Lok. 934; TMEN 1775).

yedek > Rom. jedec, edec "teferruat; yolcu eşyası, yük; çekme halatı"; edecgiŭ "seyis"; a trage la edec "yedekli gemi" (Lok. 948; TMEN 1831, 1832).

yel > Rom. iele, ̌̌ele, ele "kas şişmesi, aksama, topallama, felç; kötü peri, cin"; zilele babelor "ilkbahardaki kar firtınası, karabasan yeli" (Mey. 162; Lok. 950, 1423; Bak. 320).

yelek > Rom. ilic "uzun köylü giysisi" (Mik. 81; Mey. 142; Lok. 951; ML 9582; Rol. 209).

yılankavi > Rom. langavie "zikzak, nakışta fisto, elbiseye işlenen süslü şerit" (Lok. 969).

zıbın > Rom. zăbun, zeban, zebon, zebun, zobon "pamuklu köylü buluzu, iş tulumu; kısa kürk palto" (Mik. 86; Şay. II, 379; Lok. 737, 2176; Kak. 432; Bak. $373)$.

zıpkın > Rom. săpói "kök çapası, bir yüzü baltaya benzeyen kazma" (Bak. 243; GK).

\section{Sonuç}

Tarih boyunca geniş bir coğrafyada konuşulan ve yazılan Türkçe, pek çok farklı kültürün diliyle de etkileşim içinde olması sebebiyle hem alıcı hem de verici bir dil olmuştur. Türkçe etkilendiği kadar etkilemiş, öğrendiği kadar da öğretmiştir. Öğreticilik vasfı göz önünde tutulduğunda Türkçe bir kültür dilidir.

Birbirlerine bir şeyler öğreten toplulukların dillerinde, verici dilden gelen ödünçlemeler, bir bilgi taşıyıcısı iseler, alıcı dilde kalıcılıkları daha uzun süreli olmuştur. Bu nitelikleriyle ödünçlemeler alıcı dili zenginleştirirler.

Tarihî ilişkiler sebebiyle Türkçeden Romenceye giren sözcük sayısı (değişik kaynaklarda değişik veriler bulunmakla birlikte) bir hayli fazla olmuştur. Siyasi, iktisadi ve tarihî ilişkilerin sona ermesinden sonra bu durumla ilişkili olan ödünçlemelerin çoğu Romenceden çekilip gitmişler, bilgi ile ilişkili olan sözcük 
alıntıları ise Romencede yaşamaya devam etmişlerdir. Başlangıçta, yani Romenceye girdikleri erken dönemlerde bilinen sözlük anlamlarıyla ilişkilendirilen bu Türkçe sözcükler, zamanla asıl sözlük anlamlarından anlamsal düzeyde tam olarak kopmayıp, çoğunlukla da eski anlamlarını korumuş olmakla birlikte, yeni kavramları da edinmişlerdir. Anlam bilimi içinde anlam kayması olarak değerlendirilen bu durum, Romencenin söz varlığını zenginleştiren bir unsurdur.

Bu yazıda Türkçeden Romenceye tarihin değişik dönemlerinde giren, Türkçede taşıdıkları sözlük birimi anlamlarının yanında yeni anlamlar kazanan 208 anlam kayması örneği sözcük tespit edilmiştir. Bu sözcüklerin 11'i fiil, 197'si ise isimdir. Yine bu alıntı sözlük birimlerin yeni mecaz anlamlar kazanarak oluşturdukları deyimlerin sayısı ise 59'dur.

\section{Kisaltmalar}

bk. Bakınız.

DS Derleme Sözlüğ̈̈ I-XII (1963-1982). Ankara: TDK Yayınları.

EDPT Clauson, S. Gerard (1972). An Etymological Dictionary of Pre-ThirteenthCentury Turkish. Oxford.

Far. Farsça

GK Karaağaç, Günay (2008). Türkçe Verintiler Sözlüğü. Ankara: TDK Yayınları. İng. İngilizce

Kak. Kakuk, S. (1973). "Rescherches sur 1"historie de la langue Osmanlie des XVII scecles, Les elements osmanlis de la langue hongroise". BOH XIX, Budapest.

Lok. Lokotsch, K. (1927). Etymologisches Wörterbuch der europaischen (germanischen, romanischen und slavischen) Wörter orientalischen Ursprungs. XVII + 242. Heidelberg.

Mey. Meyer, G. (1891). Etymologisches Wörterbuch der Albanesischen Sprache. XIII+ 526. Viyana.

Mik. Miklosich, F. (1890). I. Die Türkischen Elemente in den südost-und osteuropaischen sprachen (Griechisch, Albanisch, Rumunisch, Bulgarisch, Serbisch, Kleinrussisch, Grossrussich, Polnisch). Viyana.

ML Meyer-Lübke, W. (1935). Romanisches Etymologisches Wörterbuch. Heidelberg.

Osm. Osmanlıca-Türkçe Ansiklopedik Lugat. Haz. Ferit Devellioğlu. 1997, Ankara: Aydın Kitabevi Yayınları.

OTS Ötüken Osmanlı Türkçesi Sözlüğü. Haz. Yaşar Çağbayır. 2017, Ankara: Ötüken Yayınları.

Şay. Şaineanu, L. (1900), Influenta orientala asupra limbei ti culturei romane, IIII. Bucureşti. 
T. Türkçe

TMEN Doerfer, Gerhard (1963-1975). Türkische und Mongolische Elemente im Neupersischen I-IV. Wiesbaden.

Wendt Wendt, H. F. (1960). Die Türkischen Elemente im Rumanischen. Berlin.

\section{KAYNAKÇA}

AKSAN, D. (2009). Anlambilim (Anlambilim Konuları ve Türkçenin Anlambilimi). Ankara: Engin Yayınevi.

AKSAN, D. (1995). Her Yönüyle Dil. Ankara: TDK Yayınları.

AKSU, A. (2005). "Romanya Türklerinde Kültürel Durum ve Mektep ve Aile Mecmuası". Cumhuriyet Üniversitesi Illahiyat Fakültesi Dergisi, LX/1: 11-27.

ARSLAN EROL, H. (2002). Eski Türkçeden Eski Anadolu Türkçesine Anlam Değişmeleri. Doktora Tezi, Çanakkale: Çanakkale Onsekiz Mart Üniversitesi Sosyal Bilimler Enstitüsü.

ATMACA, E. (2011). Eski Ŏ̆uz Türkçesinden Türkiye Türkçesine Söz Varlı̆̆ındaki Değişmeler ve Anlam Olayları, Doktora Tezi, Sakarya: Sakarya Üniversitesi Sosyal Bilimler Enstitüsü.

BAUBEC, A. (2017)."Romanya"da Türkoloji Araştırmaları Kapsamında Türkçe ile İlgili Leksikografik Çalışmalar". III. Uluslararası Sözlükbilimi Sempozyumu Bildiri Kitabı, 3-4 Kasım 2016, Eskişehir, s. 17-27.

BAYRAKTAR, F. S. - DAĞDEVİREN, A. (2015). "Türkçeden Bulgarcaya Geçen Sözcüklerdeki Anlam Değişmeleri Üzerine Bir Deneme". Balkan Araştırma Enstitüsü Dergisi, 4/1: 1-18.

CLAUSON, Sir G. (1972). An Etymological Dictionary of Pre-ThirteenthCentury Turkish. Oxford.

ÇAĞBAYIR, Y. (2017). Ötüken Osmanlı Türkçesi Sözlüğü. İstanbul: Ötüken Yayınları.

DEMİ, N. (2003)."Popüler Dil Tartışmalarına Dil İlişkileri Açısından Bakış". Cumhuriyetimizin 80. Yılında Türkçemiz, Ankara Ticaret Odası-Anadolu Çağdaş Eğitim Vakfi, s. 37-44. http://www.dilbilimi.net/ndemir_populer_dil.pdf (Erişim tarihi: 18.04.2021).

DERJAJ, A. (2010). "Arnavutça Türkçe Dil İlişkileri". Kastamonu Eğitim Dergisi, 18/3: 991-996.

Derleme Sözlüğ̈̈. I-XII (1963-1982). Ankara: TDK Yayınları.

DEVELLİĞLU, F. (1997). Osmanlıca-Türkçe Ansiklopedik Lugat. Ankara: Aydın Kitabevi. 
DOĞRU, F. (2013). "Kâmûs-1 Türkî'den Türkçe Sözlük'e Anlam DeğişmeleriEylemler". Turkish Studies, International Periodical For The Languages, Literature and History of Turkish or Turkic, 8/9: 1183-1222.

EKER, S. (2006)."Bosna"da Etno-Linguistik Yap1 ve Türk Dili ve Kültürü Üzerine". Millî Folklor, 72: 1-14. http://www.millifolklor.com/PdfViewer.aspx. (Erişim tarihi: 16.03.2020.)

FİLİBIC, K. (2016). Boşnakça, Hırvatça ve Strpçaya Türkçe Vasttasıyla Geçen Arapça ve Farsça Kelimelerin Ses, Şekil ve Anlam Bakımından Incelenmesi. Yüksek Lisans Tezi, İstanbul: İstanbul Üniversitesi Sosyal Bilimler Enstitüsü.

GÖKÇE， R. (2012). "Romen-Türk Kültürel Etkileşiminin Romen Diline Yansımaları". Motif Akademi Halkbilimi Dergisi, Balkan Özel Sayısı, II: 67-82.

İSİ, H. (2014). "Dil Teması ve Çoban Kelimesi Üzerine Düşünceler". Uluslararası Sosyal Araştırmalar Dergisi, The Journal of International Social Research, 7/33: 176-187.

İYIYOL, F. ve KESMECİ, A.M. (2011). "Balkan Dillerindeki Türkçe Kelimelerin Tanımlanması Problemi Üzerine Tespitler". Turkish Studies, Fall, 6/4: 621-632.

KAHRAMAN, M. (2018). "Türk Dilinden Boşnak Diline Alıntılanan Birleşik Yapılar (öbek yapılar, bileşikler ve kalıp sözler)". Asos, Uluslararası Araştırmalar Dergisi, 11/58: 99-115.

KAKUK, S. (1973). "Rescherches sur 1"historie de la langue Osmanlie des XVII scecles, Les elements osmanlis de la langue hongroise". BOH XIX, Budapest.

KARAAĞAÇ, G. (1997)."Alıntı Kelimeler Üzerine Düşünceler". Türk Dili, 552: 499-511.

KARAAĞAÇ, G. (1998). "Türkçenin Komşularıyla İlişkilerine Genel Bakış". İstanbul Üniversitesi Edebiyat Fakültesi Türk Dili ve Edebiyatı Dergisi, 28: 359406.

KARAAĞAÇ, G. (2002). Dil, Tarih ve Insan. Ankara: Akçağ Yayınları.

KARAAĞAÇ, G. (2004). Türkçenin Dünya Dillerine Etkisi. V. Lefke Edebiyat Buluşması. Ankara: Akçağ Yayınları.

KARAAĞAÇ, G. (2008). Türkçe Verintiler Sözlüğ̈̈. Ankara: TDK Yayınları.

KOCA, S. (2021). "Kamus-1 Türkî'den Günümüze Fransızca Alıntı Kelimelerde Anlam Değişmeleri". RumeliDe Dil ve Edebiyat Araştırmaları Dergisi, 22: 1-27.

KUTLAR, H. (1995). Balkan Dillerindeki Türkçe Kültür Kelimeleri I-II. Yüksek Lisans Tezi, İzmir: Dokuz Eylül Üniversitesi Sosyal Bilimler Enstitüsü.

LOKOTSCH, K. (1927). Etymologisches Wörterbuch der Europaischen (germanischen, romanischen und slavischen) Wörter orientalischen Ursprungs. Heidelberg.

MEYER, G. (1891). Etymologisches Wörterbuch der Albanesischen Sprache. Viyana. 
MİKLOSİCH, F. (1890). I. Die Türkischen Elemente in den südost-und osteuropaischen sprachen (Griechisch, Albanisch, Rumunisch, Bulgarisch, Serbisch, Kleinrussisch, Grossrussich, Polnisch). Viyana.

ÖZKAN, E. (2019). Tarama Sözlüğ̈̈'nden Kamûs-ı Türkîye Anlam Değişmeleri. Doktora Tezi, Diyarbakır: Dicle Üniversitesi Eğitim Bilimleri Enstitüsü.

ÖZKAN, F. ve BAĞDAGÜL, M. (2004)."Yabancı Dillerin Türkçenin Söz Dizimi Üzerindeki Etkisi". Bilig, Yaz, 30: 95-139.

SARI, İ. (2013). "Dil Etkileşimi Bağlamında Ses-Anlam Eşlemesi ve Türkçedeki Örnekleri". Türk Kültürü,1/ 1-27.

SAV, B. (2003). "Anlam Değişmeleri Üzerine Artzamanlı Bir İnceleme". G. $\ddot{U}$. Gazi Eğitim Fakültesi Dergisi, 23/1: 147-166.

SELÇUK, E. (2010). "Anlam Değişmeleri Üzerine Bir Gruplandırma Çalışması". Türkmen İlmi Galgınış ve Halkara Gatnaşıkları Yolunda, İlmi Makalalar Yıgındısı, Türkmenistan Ilimlar Akademiyası İlim Neşriyat1, 3:364-376.

ŞAHRU, P.U. - KİRIK, E. (2019). "Kâmûs-1 Türkî'den Çağdaş Türkiye Türkçesine Deyimlerde Anlam Değişmeleri". Sosyal ve Kültürel Araştırmalar Dergisi, 5/10: 139-162.

Tarama Sözlüğ̈̈. I-VIII (1963-1977), Ankara: TDK Yayınları.

TDK (1988). Türkçe Sözlük, 8. bs., Ankara: TDK Yayınları.

TDK (2011). Türkçe Sözlük, 11. bs., Ankara: TDK Yayınları.

UYSAL, İ. N. (2020). "Dil İlişkileri Bağlamında Popüler Türk Romanlarındaki Batı Kökenli Kelimeler". TYB Akademi Dil Edebiyat ve Sosyal Bilimler Dergisi, 29: 11-27. https://www.tybakademi.com/kitap/akademi29.pdf (Erişim Tarihi: 18.04.2021).

YALAP, H. (2016). "Türkçeden Sırpçaya Geçen Kelime ve Eklerle Bu Unsurların Sırplara Türkçe Öğretimindeki Katkısı". TÜBAR, Bahar, XXXIX: 239-259.

YILDIZ, O. ve AKGÜL, S. (2014). "Çağdaş Arnavutçada Türkçe Kökenli Alıntı Kelimelerde Görülen Fonolojik Değişimler". Türük, Dil, Edebiyat ve Halkbilimi Araştırmaları Dergisi, 2/3: 219-230.

ZENGİN, E. (2017). "Türkçenin Diğer Dillerle Etkileşimi ve Sonuçları". Uluslararası Sosyal Araştırmalar Dergisi, 10/52: 294- 299.

XNARİ, L. L. (2015). Balkan Dillerindeki Ortak Türkizmalar Sözlüğü. Pamukkale Üniversitesi Yayınları. 